\title{
Editorial to the Special Issue: Adsorption, Absorption and Thermochemical Transport Processes in Complex Porous Structures
}

\author{
H. J. Xu ${ }^{1} \cdot$ Q. G. Zhang ${ }^{2} \cdot$ G. Debenest ${ }^{3}$
}

Accepted: 7 October 2021 / Published online: 15 October 2021

(C) The Author(s), under exclusive licence to Springer Nature B.V. 2021

\begin{abstract}
The theme of coupling problems for adsorption, absorption and thermochemical transport in porous media is very important for engineering applications. Based on the submissions to the mini-symposium 22 of InterPore 2020, this special issue used this opportunity to evaluate some of these papers, and also invite some other scholars to submit their latest original research findings which are either advances in the state of the art of numerical models, molecular studies or experimental studies for new contributions. All the submissions developed existing models or methods and showed the critical engineering problems in 'Adsorption, Absorption and Thermochemical Transport Processes in Complex Porous Structures' to be presented in the journal Transport in Porous Media.
\end{abstract}

Keywords Porous media - Adsorption - Absorption - Thermochemical transport · Heat and mass transfer

Porous media refer to a special kind of solid materials with pore spaces distributed continuously on the macroscopic level (randomly on the microscopic level) and have a very wide range of applications in all walks of life. Therefore, this special issue, involving the term 'Complex Porous Structures,' paid a special attention to various aspects of fluid dynamic, heat and mass transfer as well as adsorption/absorption generally. Adsorption, absorption and the related thermochemical transport processes porous media are very important

H. J. Xu

xuhuijin@sjtu.edu.cn

Q. G. Zhang

zquanguo@163.com

G. Debenest

gerald.debenest@toulouse-inp.fr

1 China-UK Low Carbon College, Shanghai Jiao Tong University, Shanghai 200240, China

2 College of Mechanical and Electrical Engineering, Henan Agricultural University, Zhengzhou 450002, China

3 Institut de Mécanique des Fluides de Toulouse (IMFT) - Université de Toulouse, CNRS-INPT-UPS, Toulouse 31400, France 
and can find considerable applications in engineering, such as refrigeration, heat storage, CCUS (carbon capture, utilization and storage), chemical engineering and so on. Nearly all the above processes have an inherent coupling relationship between the porous material in the solid state and the fluid in the pore space. There is great potential for research in various aspects for the coupling of porous solid and fluid related to adsorption, absorption and thermochemical processes, such as fluid flow, heat and mass transfer, chemical reaction mechanisms, multi-scale models and algorithms, experimental data, and molecular dynamics study, with various applications.

This special issue began to receive submissions from October 7th, 2020 to January 11th, 2021. In response to the call for papers, a total of the seventeen papers were submitted for possible publication. Finally, twelve papers met the acceptance criteria for final publication after the rigorous peer review process. The other five submissions may have been technically correct, but were not considered appropriate for either the novelty or the scope of this special issue. The authors of paper submissions involve scholars from all over the world such as China, USA, France and Brazil. This shows the wide influence of the selected topic and the effective organization of the guest editorial team of this special issue. We hope that while solving some of the current difficulties, this special issue of the journal can also provide colleagues in the scientific community with the latest scientific results and research ideas.

The research content of the papers of this special issue includes a molecular dynamics study of water flooding in an oil-water system (Sun et al. 2020), reconstruction of porous structures (Gao et al. 2020), thermochemical heat storage (Wang et al. 2020), pore scale models for immiscible displacement (Zhang et al. 2021a), MOFs (metal-organic frameworks) screening for hydrogen storage (Wang et al. 2021a), lattice Boltzmann, LB, algorithms for interactions between fluid flow and deformable porous media (Mou and Chen 2021), adsorption characteristics of $\mathrm{CO}_{2}$ to enhance recovery of shale gas $\mathrm{CH}_{4}$ (Yang et al. 2021), multiple retention mechanisms for transport in porous media (de Oliveira Rios Filho et al. 2021), solid-fluid molecular interactions on nanoconfined fluid flow (Wang et al. 2021b), liquid transport in nanoscale porous media (Zhang et al. 2021b), effective porosity and dispersion coefficient from core flooding (Guibert et al. 2021) and numerical modeling of gasification of porous char particles in supercritical water (Fan et al. 2021). It can be seen that the accepted papers describe novel and rigorous research in the subject areas of the special issue.

This special issue introduced novel mesoporous or nanoporous materials, with advances in numerical, theoretical and experimental methods with various applications. It is also shown that molecular dynamics simulations are a promising direction for exploring microfluidic or nanofluidic characteristics in porous structures. Efficient multi-scale models for describing processes over a range of spatial and temporal scales are now being developed to understand the complex multi-physics coupling of flow, heat and mass transfer, and chemical processes at different scales. The mechanisms for modeling and interpreting chemical reactions and reactive flows in porous structures are undergoing rapid development. In general, there is potential for the subject of adsorption, absorption and thermochemical processes in various complex porous structures to grow rapidly through research with application to a wide range of engineering applications. We sincerely hope that this special issue will not only provide the scientific community with the latest progress and research overview in this field, but also prove of interest to those interested in specific applications. 
Acknowledgements This work is supported by National Natural Science Foundation of China (51876118) and National Key Research and Development Program (2018YFE0206600). We thank all authors who contributed papers to the special issue. We would like to thank all the reviewers who provided their valuable comments. Some papers are based on InterPore 2020, and we give our sincere thanks to support from InterPore 2020. We also thank all the staff of the editorial department of the journal for their cooperation in this special issue. A special thanks to the Journal Editor-in-Chief, Professor Martin Blunt, for giving us this opportunity to edit this special issue.

\section{References}

de Oliveira Rios Filho, J.C., dos Santos, A., de Lima, S.A.: Multiple retention mechanisms during transport in porous media: numerical modeling and empirical parameter's evaluation. Transp Porous Med (2021). https://doi.org/10.1007/s11242-021-01604-3

Fan, C., Zhao, Q., Xu, J., Jin, H: Modeling of single porous char particle gasification in supercritical water. Transp Porous Med (2021)

Gao, Y., Wen, Z., Deng, X., et al.: Reconstruction of carbon papers and analysis of structural and characteristic parameters through lattice Boltzmann method. Transp Porous Med (2020). https://doi.org/10. 1007/s11242-020-01510-0

Guibert, R., Horgue, P., Schumi, B., et al.: Simultaneous determinations of effective porosity and dispersion coefficient from core flooding experiments, considering chemical reactions. Transp Porous Med (2021). https://doi.org/10.1007/s11242-021-01651-w

Mou, X., Chen, Z.: Pore-scale simulation of fluid flow through deformable porous media using immersed boundary coupled lattice Boltzmann method. Transp Porous Med (2021). https://doi.org/10.1007/ s11242-021-01558-6

Sun, L., Zhang, K., Zhao, Q., et al.: Molecular dynamics study on the effects of metal cations on microscale interfacial properties of oil-water-surfactant system. Transp Porous Med (2020). https://doi.org/10. 1007/s11242-020-01501-1

Wang, M., Chen, L., Zhou, Y., et al.: Numerical simulation of the physical-chemical-thermal processes during hydration reaction of the calcium oxide/calcium hydroxide system in an indirect reactor. Transp Porous Med (2020). https://doi.org/10.1007/s11242-020-01514-w

Wang, H., Yin, Y., Li, B., et al.: High-throughput screening of metal-organic frameworks for the impure hydrogen storage supplying to a fuel cell vehicle. Transp Porous Med (2021a). https://doi.org/10.1007/ s11242-020-01527-5

Wang, H., Su, Y., Qiao, R., et al.: Investigate effects of microstructures on nanoconfined water flow behaviors from viscous dissipation perspectives. Transp Porous Med (2021b). https://doi.org/10.1007/ s11242-021-01614-1

Yang, K., Zhou, J., Xian, X., et al.: Adsorption characteristics and thermodynamic analysis of $\mathrm{CH}_{4}$ and $\mathrm{CO}_{2}$ on continental and marine shale. Transp Porous Med (2021). https://doi.org/10.1007/ s11242-021-01599-X

Zhang, L., Xu, C., Guo, Y., et al.: The effect of surface roughness on immiscible displacement using pore scale simulation. Transp Porous Med (2021a). https://doi.org/10.1007/s11242-020-01526-6

Zhang, J., Song, H., Zhu, W., et al.: Liquid transport through nanoscale porous media with strong wettability. Transp Porous Med (2021b). https://doi.org/10.1007/s11242-020-01519-5

Publisher's Note Springer Nature remains neutral with regard to jurisdictional claims in published maps and institutional affiliations. 